\title{
Identifikasi Waste Tahap Pra Analitik dengan Pendekatan Lean Hospital di Laboratorium Patologi Klinik RS XYZ Depok Jawa Barat Tahun 2021
}

\author{
Rini Prasetyo Wahyu Wijayati*, Dumilah Ayuningtyas** \\ *Ilmu Kesehatan Masyarakat Fakultas Kesehatan Masyarakat, Universitas Indonesia \\ **Administrasi Kebijakan Kesehatan Fakultas Kesehatan Masyarakat, Universitas Indonesia \\ email: rinisigit10@gmail.com
}

\begin{abstract}
The pre analytical stage is a stage that involves many health professionals starting from the time the specimen is brought in until it is ready to be analyzed. Pre analytical stage errors account for $50 \%$ to $70 \%$ laboratory error. The research aims to identify preanalytical waste and provide recommendations for improvement. This type of research is operational research with a mix method research design. The data collection process was carried out by direct observation and in-depth interviews. Specimens of 33 specimens. Qualitative data from in-depth interviews were obtained from 5 Medical Laboratory Technical Analysts (ATLM), 3 doctors on duty and 3 Head Nurses. Observation Using Time and Motion study to study the movement of specimens carried out by ATLM with time calculation. The objective of observation is to get a standard movement to complete work effectively and efficiently. Analisis using phases, lean identifying value added, non value added and waste. Exploring the root cause of the problem with the five (5) Whys approach and proposing recommendations for improvement. The results showed that $50.89 \%$ of activities did not provide added value,49.10\% provided added value. Waste found waiting for samples to be sent back, waiting for inspection orders (waiting), no specimen orders, hemolysis, non-standard identity stickers (defect), repair of identity stickers (over processing). Recommendations for improvement are
\end{abstract}

proposals for phlebotomy training, reeducation on handling laboratory specimens for nurses, SOP for handing over specimens, making laboratory examination packages.

Keywords: Waste, Pre Analytical Stage, Concept Lean

\section{PENDAHULUAN}

Laboratorium klinis memiliki peran penting dalam penegakan diagnosis, pemantauan pasien selama masa rawat inap, serta pencegahan dan pengobatan terhadap penyakit oleh sebab itu pelayanan laboratorium berupaya menjaga dan memastikan proses pelayanan terjamin mutunya. ${ }^{1}$

Hasil pemeriksaan laboratorium yang cepat dan tepat waktu merupakan aspek penting yang wajib diberikan oleh laboratorium klinis. Waktu penyelesaian hasil laboratorium yang cepat dinilai penting dari sudut pandang klinisi dan pasien ${ }^{2}$

Setiap tahapan pemeriksaan di laboratorium mengacu kepada GLP (Good Laboratory Prosedure) agar setiap pemeriksaan mendapatkan hasil yang akurat. Kesalahan pra analitik merupakan kesalahan yang terjadi dan dimulai ketika pemeriksaan laboratorium diorder oleh dokter sampai sampel pemeriksaan tiba di laboratorium dan siap analisis. Sebagian besar kesalahan dalam hasil pemeriksaan laboratorium terjadi pada tahap pra analitik. Oleh karena itu tahap pra analitik merupakan elemen penting bagi 
laboratorium serta membutuhkan banyak perhatian. Penelitian melaporkan bahwa 61.9\% kesalahan terjadi selama pra analitik, diantaranya spesimen yang tidak mencukupi secara kuantitas maupun kualitas spesimen menyumbang sebesar $60 \%$ kesalahan di tahap pra analitik ${ }^{3}$.

Tahap pra analitik merupakan salah satu tahapan paling kompleks untuk dikendalikan. Tahap pra analitik memiliki serangkaian variabel dan beberapa titik kritis yang terkait dengan berbagai kesalahan. Tahapan tersebut diantaranya persiapan pasien, proses pengambilan spesimen, transportasi, penerimaan dan pelabelan sampel, proses sentrifuse, distribusi sampel dan persiapan spesimen untuk dianalisis.

Tahap pra analitik mencakup serangkaian proses yang sulit didefinisikan karena dapat terjadi ditempat dan waktu yang berbeda. Kesalahan tahap pra analitik dapat mencapai hingga 70\% dari total kesalahan laboratorium. Dampak dari kesalahan ditahap ini tidak dapat diabaikan, karena informasi yang diberikan dari hasil laboratorium klinis dapat memengaruhi hingga $60-70 \%$ keputusan klinis. ${ }^{5}$. Sebagian besar kesalahan diproses laboratorium berada ditahap pra analitik. Tahap pra analitik menyumbang kesalahan hasil laboratorium sebesar 50\% hingga 70\% termaksud di dalamnya masalah identifikasi pasien dan sampel. ${ }^{6}$

Proses pra analitik dimulai dari permintaan dokter untuk dilakukan pemeriksaan laboratorium, persiapan sampel untuk pemeriksaan, persiapan pasien, transportasi sampel, pengambilan sampel, persiapan sampel, dan penyimpanan sampel. Hal tersebut dapat menjadi sumber kesalahan utama dalam penentuan diagnosis laboratorium. Dimasa lalu fokus utama laboratorium pada kesalahan tahap analitik. Namun, saat ini laboratorium lebih berkonsentrasi pada tahap persiapan pra analitik dan paska analitik karena dapat meningkatkan frekuensi kesalahan. ${ }^{1}$

Penelitian yang dilakukan oleh Brijesh Mukherjee dan Saurav Patra (2013) menjelaskan bahwa kesalahan pra analitik mempengaruhi hasil terhadap uji laboratorium sebesar $46-68.2 \%$ dari total kesalahan. Tipe kesalahan tersebut disebabkan karena kualitas sampel yang tidak akurat (47\%), identifikasi pasien yang salah $(26.8 \%)$, tidak adanya order pemeriksaan dari dokter (14\%) dan penggunaan tabung pemeriksaan yang tidak sesuai $(0.6 \%)^{7}$. Penelitian Dereen Najat (2017) di Laboratroium Klinik Irak menjelaskan prevalensi penanganan sampel yang tidak tepat selama tahap pra-analitik sebesar 39\% dengan alasan utama kesalahan terjadi pada sampel yang mengalami hemolysis (9\%), kesalahan identifikasi terhadap sampel (8\%) dan kejadian sampel beku (clotted) sebesar 6\%. ${ }^{8}$

RS XYZ menetapkan target indikator mutu waktu tunggu hasil pemeriksaan laboratorium 120 menit. Tahun 2020 Capaian indikator mutu RS XYZ mencapai 70\% (target indikator mutu yang ditetapkan $80 \%$ setiap bulan). Data waktu tunggu hasil pemeriksaan laboratorium bulan Januari sampai Febuari 2021 terdapat $18 \%$ hasil pemeriksaan laboratorium lebih dari 120 menit.

Lean Management merupakan pendekatan sistem secara keseluruhan dan fokus mengidentifikasi serta menghilangkan aktivitas non added value dari suatu proses. Lean melibatkan semua orang dalam organisasi dalam upaya menghilangkan segala bentuk pemborosan dimana pun dalam prosesnya. Tujuan Lean menggunakan lebih sedikit sumber daya manusia, lebih sedikit inventaris, lebih sedikit ruang dan waktu untuk menghasilkan produk berkualitas tinggi seefisien dan seekonomis mungkin sekaligus responsif terhadap kebutuhan dan permintaan pelanggan. ${ }^{21}$

Prinsip Lean meningkatkan proses kerja, menghemat waktu, biaya serta persediaan. Dalam jangka panjang dapat meningkatkan kecepatan, kualitas, profitabilitas serta kepuasan pelanggan. ${ }^{(11}$ Lean mengidentifikasi dan menghilangkan pemborosan. Waste atau pemborosan diartikan sebagai segala kegiatan atau hal yang tidak memberikan nilai tambah (non value added NVA) dan tidak menyerap sumber daya. ${ }^{11}$ Kategori waste berdasarkan konsep Lean terdiri dari overproduction, delays (waiting time), transportation, over processing, inventories, motions dan defect. $^{12}$ 
Tujuan dari penelitian ini mengidentifikasi pemborosan atau waste yang terjadi ditahap pra analitik serta memberikan rekomendasi perbaikan pemeriksaan laboratorium tahap pra analitik.

\section{METODE PENELITIAN}

Jenis penelitian yang digunakan adalah penelitian operasional dengan desain penelitian mix method. Penelitian operasional bertujuan memberikan rekomendasi terhadap masalah operasional dalam pelaksanaan kegiatan dimana hasilnya dapat membantu memecahkan masalah dengan tetap menggunakan metode ilmiah berdasarkan permasalahan yang ditemukan di lapangan. Lokasi penelitian dilakukan di Laboratorium Patologi Klinik RS XYZ Depok Jawa Barat. Penelitian dilakukan 30 April sampai $20 \mathrm{Mei}$ 2021.

Data kuantitatif didapatkan dari hasil observasi langsung proses pemeriksaan laboratorium. Data kualitatif diperoleh dari hasil wawancara mendalam dengan melibatkam informan lima (5) Analis Teknis Medik Laboratorium (ATLM), tiga (3) dokter jaga dan tiga (3) Kepala Perawat.

Jumlah sampel pemeriksaan dihitung menggunakan rumus estimasi rata rata menurut Lemeshow 1991 didapatkan jumlah sampel sebanyak 33 sampel. Observasi non partisipan menggunakan metode Time and Motion study dengan mempelajari pergerakan sampel yang dikerjakan ATLM ditahap pra analitik lalu menghitung waktu setiap kegiatan tahap pra analitik menggunakan stopwatch. Observasi langsung bertujuan mendapatkan pergerakan standar sampel ditahap pra analitik secara efektif dan efisien

Kriteria inklusi dari spesimen yang diambil yaitu spesimen dari unit Rawat Inap dan Instalasi Gawat Darurat yang dapat dikerjakan di laboratorium Patologi Klinik RS XYZ (bukan spesimen yang di rujuk ke luar), spesimen yang diperiksa pada hari Senin sampai Sabtu. Kriteria esklusi spesimen yang dirujuk ke rumah sakit lain, serta spesimen yang tidak layak

Analisis penelitian menggunakan tahapan Lean dengan menggambarkan proses pra analitik pemeriksaan laboratorium, mengidentifikasi kegiatan yang memberikan nilai tambah (added value), kegiatan yang tidak memberikan nilai tambah (non added value) dan merupakan pemborosan (waste). Menggali akar penyebab masalah melalui wawancara mendalam menggunakan pendekatan 5 Whys serta memberikan rekomendasi perbaikan. Penelitian sudah melalui proses kaji etik dari Fakultas Kesehatan Masyarakat Universitas Indonesia dengan nomor etik penelitian 110/UN2.F10.D11/PPM.00.02/2021 dan terbit pada tanggal 3 April 2021.

\section{HASIL DAN PEMBAHASAN}

Berikut alur pemeriksaan laboratorium tahap pra analitik berdasarkan hasil observasi langsung di Laboratorium Patologi Klinik RS XYZ Depok Jawa Barat 30 April sampai 20 Mei 2021.

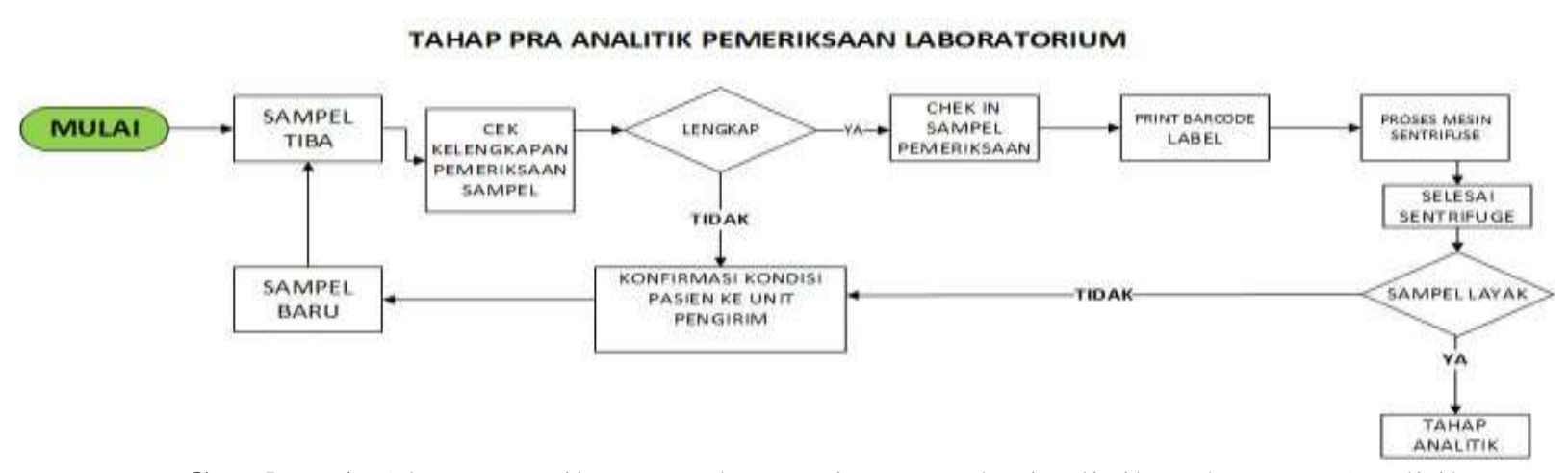

Gambar 1. Alur Pemeriksaan Laboratorium Patologi Klinik Tahap Pra Analitik 
Berdasarkan gambar diatas proses pemeriksaan laboratorium pra analitik dimulai ketika spesimen dari rawat inap dan Instalasi Gawat Darurat (IGD) dikirim ke laboratorium oleh HCA (Health Care Assistant) serah terima spesimen dengan ATLM lalu mencatat spesimen yang dikirim dilembar serah terima. ATLM melakukan proses identifikasi spesimen melalui Sistem Informasi Rumah Sakit (SIMRS) dengan mencocokan identitas pasien, kesesuaian order permintaan dokter, kualitas spesimen apakah memenuhi syarat baik dari kesesuaian penggunaan tabung, volume spesimen, apakah hemolisis atau tidak. Jika spesimen tidak layak maka ATLM akan menghubungi unit pengirim spesimen untuk konfirmasi. Spesimen yang dinyatakan layak akan berlanjut ke proses check in spesimen ke sistem LIS (Laboratory
Information System) lalu proses sentrifuse spesimen (disesuaikan dengan jenis tabung dan pemeriksaan). Proses sentrifus menggunakan mesin sentrifus selama kurang lebih 10 menit. Selesai proses sentrifus, jika spesimen layak (tidak terjadi hemolisis) dilanjut ke proses berikut analitik (sampai tahap ini tahap pra analitik selesai. Spesimen yang mengalami hemolisis setelah proses sentrifus ATLM akan meminta ke unit pengirim agar dikirimkan spesimen baru.

Dari alur pemeriksan laboratorium tahap pra analitik tersebut dibagi 3 proses yaitu proses serah terima, check in spesimen dan proses sentrifus spesimen. Berikut hasil perhitungan kegiatan value added dan non value added tahap pra analitik.

Tabel 1. Perhitungan Value Added dan Non Value Added Pemeriksan Laboratorium Tahap Pra Analitik

\begin{tabular}{lccc}
\hline \multicolumn{1}{c}{ Proses } & $\begin{array}{c}\text { Proses Serah } \\
\text { Terima }\end{array}$ & $\begin{array}{c}\text { Proses Check In } \\
\text { Spesimen }\end{array}$ & Proses Sentrifuse \\
\hline Total VA (hh:mm:ss) & $00: 41: 29$ & $00: 54: 43$ & $5: 51: 53$ \\
Total NVA (hh:mm:ss) & $00: 47: 56$ & $1: 50: 26$ & $5: 06: 03$ \\
Total Cycle Time (hh:mm:ss) & $1: 29: 25$ & $2: 45: 09$ & $10: 57: 56$ \\
\% VA & $46.39 \%$ & $33.13 \%$ & $53.48 \%$ \\
\% NVA & $53.61 \%$ & $66.87 \%$ & $46.52 \%$ \\
Total Lead Time (hh:mm:ss) & & $15: 12: 30$ & \\
Rata Rata Lead Time & & $00: 27: 39$ & \\
(hh:mm:ss) & & & \\
Waktu Minimal & & $00: 11: 00$ & \\
Waktu Maksimal & & $2: 27: 12$ & \\
Total \% VA & & $49.10 \%$ & \\
Total \% NVA & & $50.89 \%$ & \\
\hline
\end{tabular}

Dari tabel diatas total lead time pemeriksaan tahap pra analitik 15 jam 12 menit 30 detik, dengan rata rata waktu pemeriksaan yaitu 27 menit 39 detik. Waktu minimal tahap pra analitik 11 menit 0 detk dan waktu maksimal 2 jam 27 menit 12 detik. Kegiatan tahap pra analitik yang tidak memberikan nilai tambah (non value added) yang merupakan waste bagi pasien dan dokter sebesar $50.89 \%$. Lebih besar dibanding dengan kegiatan yang memberikan nilai tambah (value added) yaitu $49.10 \%$. Kegiatan tahap pra analitik yang tidak memberikan nilai tambah (non value added) paling banyak terjadi ditahap proses serah terima dan proses check in spesimen.
Hasil dari wawancara mendalam dari informan kendala ditahap pra analitik dijelaskan pada kutipan sebagai berikut:

"Dari ruangan kadang ada ketidaksesuaian menggunakan stiker, stiker kadang menutupi tabung vacutainer keseluruhan, kadang suka pakai tabung yang ga sesuai, volume sampel kadang kurang dan lebih kadang lisis" Informan6

"kendala saat pengiriman sampel stiker menggunakan micropore kemungkinan darah cito, stiker tidak tersedia ya uda yang penting di tandain di kasi nama, HCA ambil mungkin tidak lakukan croscek karena belum tentu handovernya oleh perawat secara langsung dan HCA tidak infokan bahwa stiker yang digunakan tidak sesuai” Informan9 
Ordernya dari GP (general practitioner) kendalanya seringkali lupa dan mesti sering dingetkan apalagi kondisi di IGD lagi hectic"Informan7

Tahapan pra analitik melibatkan proses mulai dari permintaan pemeriksaan laboratorium yang dibuat oleh dokter, persiapan spesimen untuk pemeriksaan, persiapan pasien, pengumpulan, transportasi dan penyimpanan spesimen.Tahapan tersebut berkontribusi dalam sumber kesalahan utama dalam diagnosis laboratorium. ${ }^{1}$ Persiapan dan penanganan spesimen yang tidak tepat dapat mengakibatkan sampel hemolisis, clotting dan jumlah volume spesimen tidak mencukupi. ${ }^{13}$ Sampel hemolisis umumnya disebabkan berbagai kondisi saat tahap pengumpulan sampel. Sampel hemolisis tidak dapat diproses ke tahap selanjutnya karena berdampak terhadap hasil pemeriksaan kimia darah. ${ }^{14}$ Hasil penelitian Dereen Najat (2017) di Laboratorium Klinik Irak menjelaskan bahwa tingginya prevalensi penanganan sampel yang tidak tepat selama tahap pra analitik sebesar 39\% dengan alasan utama kesalahan tersebut terjadi pada sampel yang mengalami hemolysis sebesar $9 \% .{ }^{8}$.

Hasil observasi kegiatan pemeriksaan pra analitik yang masuk dalam kegiatan value added, non value added serta kategori waste disetiap tahap dijelaskan pada tabel berikut.

Tabel 2. Klasifikasi Value added, Non Value Added dan Kategori Waste Pemeriksaan Laboratorium Tahap Pra Analitik

\begin{tabular}{|c|c|c|c|}
\hline $\begin{array}{l}\text { Siklus } \\
\text { Proses }\end{array}$ & Aktivitas Value Added (VA) & Aktifitas Non Value Added (NVA) & Kategori Waste \\
\hline $\begin{array}{l}\text { Proses } \\
\text { Serah }\end{array}$ & Proses serah terima spesimen & Menunggu spesimen diambil oleh ATLM & Delays (waiitng time) \\
\hline Terima & & Menunggu spesimen dikirim ulang & Delays (waiitng time) \\
\hline $\begin{array}{l}\text { Proses } \\
\text { Check in }\end{array}$ & $\begin{array}{l}\text { Proses check in spesimen di } \\
\text { SIMRS dan LIS }\end{array}$ & $\begin{array}{l}\text { Penggunaan stiker identitas yang tidak } \\
\text { standar }\end{array}$ & Defect \\
\hline Specimen & & Tidak order pemeriksaan di SIMRS & Defect \\
\hline $\begin{array}{l}\text { Proses } \\
\text { Sentrifus }\end{array}$ & Proses sentrifus spesimen & $\begin{array}{l}\text { Labeling spesimen yang tidak standar } \\
\text { Spesimen hemolisis }\end{array}$ & $\begin{array}{l}\text { Overprocessing } \\
\text { Defect }\end{array}$ \\
\hline
\end{tabular}

Kegiatan pra analitik yang paling banyak tidak memberikan nilai tambah (non value added) terjadi pada tahap serah terima dan check in spesimen. Kegiatan yang tidak memberikan nilai tambah disebabkan teknik penanganan spesimen pemeriksaan yang dikirim dari rawat inap dan IGD belum berjalan dengan efektif, mekanisme serah terima spesimen antara petugas kesehatan belum efektif. Tahap pra analitik memiliki serangkaian variabel dan beberapa titik kritis yang terkait dengan berbagai kesalahan. Tahapan tersebut diantaranya persiapan pasien, proses pengambilan spesimen, transportasi, penerimaan dan pelabelan sampel, proses sentrifuse, distribusi sampel dan persiapan spesimen untuk dianalisis. ${ }^{4}$ Hal tersebut berdampak menambah lamanya waktu tunggu tahap pra analitik. Dalam konsep Lean pemborosan disebut delays (waiting time) dan defect $^{9}$

\section{Identifikasi Waste Pada Kegiatan Pra Analitik}

Dari tujuh pemborosan Lean hanya tiga pemborosan yang dapat diidentifikasi dalam penelitian ini. Aktifitas tahap pra analitik yang dikategorikan sebagai pemborosan (waste) terlihat dari tabel berikut. 
Tabel 2 Identifikasi Waste Tahap Pra Analitik

\begin{tabular}{|c|c|c|c|c|}
\hline No & Jenis Waste (What) & $\begin{array}{l}\text { Sumber } \\
\text { (Where) }\end{array}$ & $\begin{array}{l}\text { Waktu Terjadi } \\
\text { (When) }\end{array}$ & $\begin{array}{l}\text { Alasan Terjadi } \\
\text { (Why) }\end{array}$ \\
\hline \multicolumn{5}{|c|}{ Delays (waiting time) } \\
\hline 1 & $\begin{array}{l}\text { Menunggu sampel } \\
\text { baru dikirim ulang }\end{array}$ & $\begin{array}{l}\text { Sampel berasal dari } \\
\text { unit rawat inap }\end{array}$ & $\begin{array}{l}\text { Saat proses } \\
\text { sentrifugasi selesai }\end{array}$ & $\begin{array}{lr}\text { Sampel } & \text { hemolisis } \\
\text { setelah } & \text { proses } \\
\text { sentrifuse } & \end{array}$ \\
\hline 2 & $\begin{array}{lr}\text { Menunggu } & \text { sampel } \\
\text { di ambil } & \text { oleh } \\
\text { ATLM } & \\
\end{array}$ & $\begin{array}{l}\text { Loket penerimaan } \\
\text { sampel }\end{array}$ & $\begin{array}{l}\text { Sampel tiba di } \\
\text { laboratorium }\end{array}$ & $\begin{array}{l}\text { ATLM tidak standby } \\
\text { di loket penerimaan } \\
\text { sampel }\end{array}$ \\
\hline \multicolumn{5}{|c|}{ Defect } \\
\hline 3 & $\begin{array}{lr}\text { Tidak ada } & \text { order } \\
\text { pemeriksaan } & \\
\text { laboratorium } & \text { di } \\
\text { SIMRS } & \end{array}$ & IGD & $\begin{array}{l}\text { Proses check in } \\
\text { sampel }\end{array}$ & $\begin{array}{l}\text { Dokter tidak } \\
\text { melakukan proses } \\
\text { order pemeriksaan } \\
\text { laboratorium }\end{array}$ \\
\hline 4 & $\begin{array}{l}\text { Stiker identitas } \\
\text { pasien tidak standar }\end{array}$ & Rawat Inap & $\begin{array}{l}\text { Proses check in } \\
\text { sampel }\end{array}$ & $\begin{array}{l}\text { Stiker identitas } \\
\text { pasien habis, Stiker } \\
\text { baru belum tersedia }\end{array}$ \\
\hline 5 & Sampel hemolisis & IGD & Sentrifuse & $\begin{array}{l}\text { Belum merata proses } \\
\text { edukasi tentang } \\
\text { penanganan } \\
\text { spesimen } \\
\text { laboratorium }\end{array}$ \\
\hline \multicolumn{5}{|c|}{ Overprocessing } \\
\hline 6 & $\begin{array}{lr}\text { Perbaikan } & \text { stiker } \\
\text { identitas } & \text { pasien } \\
\text { pada tabung sampel }\end{array}$ & Rawat Inap & $\begin{array}{l}\text { Proses check in } \\
\text { sampel }\end{array}$ & $\begin{array}{l}\text { Stiker identitas } \\
\text { pasien menutupi } \\
\text { seluruh tabung darah }\end{array}$ \\
\hline
\end{tabular}

Tabel diatas menggambarkan bahwa pemborosan adalah defect, over processing dan delays (waiting time). Waste banyak terjadi ditahap pra analitik. Sumber utama dari waste disebabkan jumlah ATLM belum sesuai dengan analisis beban kerja, belum ada penugasan ATLM per station pemeriksaan disetiap shift, serta beberapa ATLM fresh graduate. Didapatkan spesimen hemolisis setelah proses sentrifus yang berdampak dibutuhkan spesimen baru untuk diproses kembali. Adanya antrian spesimen di loket penerimaan spesimen, serta ditemukan beberapa pengiriman spesimen yang belum dilakukan proses order oleh dokter jaga.

\section{Analisis Masalah}

Tahap selanjutnya adalah fase analisis masalah. Tahap analisis masalah dilakukan dengan metode 5 Whys. Proses menggali informasi didapatkan dari wawancara mendalam dengan melibatkan ATLM (Analis Teknis Laboratorium Medik), Dokter jaga dan perawat Berikut hasil analisis masalah berdasarkan hasil pengamatan yang terjadi dan proses wawancara mendalam :

Tabel 3 Analisis Masalah Pemborosan (Waste) Tahap Pra Analitik

\begin{tabular}{|c|c|c|c|c|}
\hline $\begin{array}{c}\text { Why } \\
1\end{array}$ & $\begin{array}{c}\text { Why } \\
2\end{array}$ & $\begin{array}{c}\text { Why } \\
3\end{array}$ & $\begin{array}{c}\text { Why } \\
4\end{array}$ & $\begin{array}{c}\text { Why } \\
5\end{array}$ \\
\hline \multicolumn{5}{|c|}{ Delays (waiting time) } \\
\hline $\begin{array}{l}\text { Menunggu sampel } \\
\text { baru di kirim } \\
\text { ulang }\end{array}$ & $\begin{array}{l}\text { Sampel hemolisis } \\
\text { setelah proses } \\
\text { sentrifugasi }\end{array}$ & $\begin{array}{l}\text { Belum meratanya } \\
\text { sosialisasi } \\
\text { Penanganan } \\
\text { Spesimen } \\
\text { Laboratorium }\end{array}$ & $\begin{array}{l}\text { Belum ada } \\
\text { pelatihan } \\
\text { penanganan } \\
\text { spesimen untuk } \\
\text { perawat }\end{array}$ & \\
\hline $\begin{array}{l}\text { Antrian sampel } \\
\text { menunggu di } \\
\text { ambil ATLM }\end{array}$ & $\begin{array}{l}\text { Belum ada ATLM } \\
\text { yang berjaga di } \\
\text { loket penerimaan }\end{array}$ & $\begin{array}{l}\text { ATLM masih } \\
\text { berproses di station } \\
\text { lain }\end{array}$ & $\begin{array}{l}\text { Belum ada } \\
\text { penempatan ATLM } \\
\text { di setiap station } \\
\text { pemeriksaan }\end{array}$ & $\begin{array}{l}\text { Belum ada SPO yang } \\
\text { mengatur } \\
\text { ATLM di setiap } \\
\text { station } \\
\text { pemeriksaan.Jumlah }\end{array}$ \\
\hline
\end{tabular}




\begin{tabular}{|c|c|c|c|c|}
\hline & & & & $\begin{array}{l}\text { ATLM belum sesuai } \\
\text { Analisis Beban Kerja }\end{array}$ \\
\hline \multicolumn{5}{|l|}{ Defect } \\
\hline $\begin{array}{l}\text { Tidak ada order } \\
\text { pemeriksaan } \\
\text { laboratorium di } \\
\text { sistem informasi } \\
\text { manajemen rumah } \\
\text { sakit (SIMRS) }\end{array}$ & $\begin{array}{l}\text { Dokter masih } \\
\text { melakukan tindakan } \\
\text { saat sampel dibawa } \\
\text { ke laboratorium }\end{array}$ & $\begin{array}{l}\text { Dokter tidak segera } \\
\text { melakukan order } \\
\text { pemeriksaan } \\
\text { laboratorium }\end{array}$ & $\begin{array}{l}\text { Order pemeriksaan } \\
\text { laboratorium di } \\
\text { input satu persatu } \\
\text { ke dalam SIMRS }\end{array}$ & $\begin{array}{l}\text { Belum ada cara atau } \\
\text { sistem yang } \\
\text { memudahkan } \\
\text { (menyederhanakan) } \\
\text { proses order } \\
\text { pemeriksaan } \\
\text { laboratorium. }\end{array}$ \\
\hline $\begin{array}{l}\text { Ketidakkonsisten } \\
\text { penggunan stiker } \\
\text { identitas pasien }\end{array}$ & $\begin{array}{lr}\text { Tidak } & \text { tersedianya } \\
\text { stiker } & \text { identitas } \\
\text { pasien } & \end{array}$ & $\begin{array}{l}\text { Stiker identitas } \\
\text { pasien habis }\end{array}$ & $\begin{array}{l}\text { Rawat inap tidak } \\
\text { bisa melakukan } \\
\text { printer stiker } \\
\text { identitas pasien } \\
\text { secara mandiri }\end{array}$ & $\begin{array}{l}\text { Rawat inap tidak } \\
\text { tersedia mesin printer } \\
\text { label. }\end{array}$ \\
\hline $\begin{array}{l}\text { Spesimen } \\
\text { hemolisis }\end{array}$ & $\begin{array}{l}\text { Proses pengambilan } \\
\text { spesimen dari rawat } \\
\text { inap masih dibantu } \\
\text { oleh perawat }\end{array}$ & $\begin{array}{l}\text { Belum meratanya } \\
\text { edukasi penanganan } \\
\text { spesimen } \\
\text { laboratorium }\end{array}$ & $\begin{array}{l}\text { Belum ada } \\
\text { pelatihan } \\
\text { penanganan } \\
\text { spesimen untuk } \\
\text { perawat }\end{array}$ & \\
\hline \multicolumn{5}{|l|}{ Overprocessing } \\
\hline $\begin{array}{l}\text { Perbaikan stiker } \\
\text { identitas pasien }\end{array}$ & $\begin{array}{l}\text { Ketidakkonsistenan } \\
\text { dalam melakukan } \\
\text { penempelan stiker } \\
\text { identitas pasien di } \\
\text { tabung sampel } \\
\text { dengan benar }\end{array}$ & $\begin{array}{l}\text { Belum meratanya } \\
\text { informasi mengenai } \\
\text { tehnik labelling } \\
\text { stiker identitas } \\
\text { pasien yang benar }\end{array}$ & $\begin{array}{l}\text { Belum meratanya } \\
\text { sosialisasi mengenai } \\
\text { Penanganan } \\
\text { Spesimen } \\
\text { Laboratorium }\end{array}$ & $\begin{array}{l}\text { Belum ada pelatihan } \\
\text { penanganan } \\
\text { spesimen untuk } \\
\text { perawat }\end{array}$ \\
\hline
\end{tabular}

Quality assurance di Laboratorium Klinik memiliki peran penting dalam proses validasi serta memastikan hasil pemeriksaan dapat diterima secara klinis. Tahap pra analitik meliputi persiapan pasien sebelum pemeriksaan, ketepatan identifikasi pasien, cara pengumpulan sampel yang baik, proses transportasi serta penyimpanan sampel. Banyak hal dapat terjadi jika proses praanalitik tidak dikelola dengan baik dan benar. Oleh sebab itu kepatuhan terhadap peraturan serta standar operasional prosedur dapat membantu meminimalkan kesalahan tahap pra analitik. ${ }^{14}$

Waste delays (waiting time) berdasarkan hasil pengamatan terjadi ketika sampel mengalami hemolisis setelah proses sentrifugasi, petugas ATLM menginformasikan kondisi tersebut ke unit rawat inap agar dikirim kembali spesimen yang baru. Waktu tunggu sampai ATLM menerima kembali spesimen baru dari unit rawat inap memberikan dampak memanjangnya waktu tunggu tahap pra analitik. Minimnya pengetahuan petugas dikarenakan belum tersosialisasi tentang Panduan teknik penanganan spesimen yang benar dapat berdampak proses penanganan spesimen. Selain itu belum terpenuhinya jumlah ATLM sesuai kebutuhan, berdasarkan Berdasarkan analisis beban kerja diperlukan 25 ATLM sedangkan saat ini jumlah ATLM yang ada baru 20. Jumlah tenaga yang banyak dapat mengakibatkan operasional laboratorium tidak efektif, namun jumlah tenaga yang kurang meningkatkan potensi terjadinya kesalahan dan memperpanjang waktu tunggu hasil pemeriksaan ${ }^{22}$

Faktor lain yang menjadi masalah yaitu belum efektifnya mekanisme serah terima spesimen dikarenakan belum adanya standar operasional prosedur mengenai serah terima spesimen. Diketahui HCA (Health Care Assistance) yang bertugas mengantar spesimen belum pernah mendapatkan sosialiasasi mengenai prosedur serah terima yang baik. Dokumen serah terima spesimen yang tersedia di loket penerimaan laboratorium belum mencakup hal yang perlu diperhatikan seperti ketepatan identifikasi pasien, informasi order pemeriksaan laboratorium serta posisi label identifikasi yang sudah tepat. Komunikasi dan serah terima yang efektif selain dapat mengurangi 
risiko terjadinya kesalahan dalam proses pengantaran spesimen, juga menjadi point penting saling kroscek dimulai dari perawat yang menerima instruksi dan pengambilan spesimen, saling mengingatkan antar perawat dengan HCA sehingga jika terdapat ketidaksesuain segera teridentifikasi. Serah terima yang efektif dapat mengurangi risiko terjadinya insiden keselamatan pasien dan meningkatkan kualitas pelayanan. ${ }^{23}$

Waste defect kegiatan pemeriksaan pra analitik karena tidak adanya order pemeriksaan laboratorium di SIMRS (Sistem Informasi Manajemen Rumah Sakit) ketika sampel pemeriksaan dikirim ke laboratorium. Proses order pemeriksaan laboratorium yang diinput satu per satu berpotensi menimbulkan order pemeriksaan tidak dilakukan dengan konsisten terutama ketika kondisi di Instalasi Gawat Darurat sedang penuh pasien. Penggunaan label identifikasi yang tidak standar disebabkan stiker identitas pasien tidak tersedia (habis), Unit Rawat Inap tidak tersedia mesin printer stiker label identitas pasien. Belum adanya standar operasional prosedur mengenai tata cara serah terima sampel. Proses serah terima yang baik serta pemahaman HCA mengenai pentingnya ketepatan identifikasi dengan penggunaan stiker identitas yang standar diharapkan penggunaan label stiker pasien yang tidak

\section{Rekomendasi Perbaikan}

Berdasarkan analisis masalah 5 Whys, berikut rekomendasi perbaikan yang dapat standar dapat segera teridentifikasi. Identifikasi pasien merupakan langkah awal saat dalam pengambilan spesimen darah. Tujuan pertama The Joint Commission National Patient Safety adalah ketepatan identifikasi pasien. Kesalahan dalan melakukan identifikasi pasien berdampak terhadap buruknya hasil klinis, karena kemungkinan terjadi salah diagnosis dan kesalahan dalam pemberian terapi. ${ }^{15}$

Waste overprocessing mencakup proses tambahan yang tidak memberikan nilai tambah atau aktifitas kerja yang tidak diperlukan atau tidak efisien ${ }^{12}$. Waste Over processing yang terjadi selama periode pengamatan disebabkan perbaikan stiker identitas pasien pada tabung pemeriksaan. Rata rata waktu yang diperlukan untuk memperbaiki stiker identitas pasien membutuhkan waktu berkisar 1 menit 30 detik. Perbaikan stiker bertujuan agar ATLM dapat mengidentifikasi apakah volume sampel sudah sesuai dengan kebutuhan serta menilai kelayakan sampel untuk diproses ke tahap berikutnya. Belum meratanya sosialisasi mengenai Panduan teknis penanganan spesimen laboratorium ke Unit Rawat Inap memberikan kontribusi dalam meningkatkan waste overprocessing di Laboratorium Klinik.

diberikan sebagai upaya perbaikan tahap pra analiti

Tabel 3 Rekomendasi Perbaikan Masalah Tahap Pra Analitik

\begin{tabular}{|c|c|c|}
\hline No & Rekomendasi Perbaikan & Lean Tools \\
\hline 1 & $\begin{array}{l}\text { Re edukasi ke unit rawat inap, Instalasi Gawat Darurat dan ATLM mengenai Panduan } \\
\text { Teknis Penanganan Spesimen Laboratorium dan komunikasi efektif ketika serah } \\
\text { terima }\end{array}$ & Standardized Work \\
\hline 2 & $\begin{array}{l}\text { Pelatihan Phlebotomy untuk rawat inap, Instalasi Gawat Darurat dan ATLM fresh } \\
\text { graduate. Pelatihan komunikasi efektif terutama serah terima yang baik dan benar }\end{array}$ & Standardized Work \\
\hline 3 & $\begin{array}{l}\text { Pembagian flayer edukasi mengenai penggunaan tabung sampel yang benar, proses } \\
\text { labeling yang sesuai serta penggunaan stiker identifikasi pasien yang standar diberikan } \\
\text { ke Unit Rawat Inap dan Instalasi Gawat Darurat }\end{array}$ & Visual management \\
\hline 4 & $\begin{array}{l}\text { Pembuatan standar paket pemeriksaan laboratorium Instalasi Gawat Darurat untuk } \\
\text { menyederhanakan proses input order pemeriksaan laboratorium di SIMRS }\end{array}$ & Standardized Work \\
\hline 5 & Pengajuan mesin printer stiker identitas di rawat inap & Standardized Work \\
\hline 6 & Penambahan jumlah ATLM agar kebutuhan sesuai Analisis Beban Kerja & Standardized Work \\
\hline 7 & $\begin{array}{l}\text { Pembuatan SPO } \\
\text { - } \quad \text { Penugasan ATLM di masing masing station mesin pemeriksaan } \\
\text { - }\end{array}$ & Standardized Work \\
\hline 8 & $\begin{array}{l}\text { Pembentukan Tim Phlebotomy dari ATLM ketika Analisis Beban Kerja ATLM } \\
\text { terpenuhi }\end{array}$ & Standardized Work \\
\hline
\end{tabular}


Standardized work merupakan cara terbaik dalam menyelesaikan aktivitas dengan aman dengan hasil yang tepat dan kualitas tinggi menggunakan sumber daya sesedikit mungkin. Standardized work merupakan salah satu upaya perbaikan dari pendekatan lean dalam mengurangi pemborosan (waste) ${ }^{16}$

Berdasarkan hasil pengamatan didapatkan waste waiting time merupakan waste terlama karena menunggu sampel baru dikirim dari unit pelayanan karena sampel mengalami hemolisis. Sampel hemolysis dapat disebabkan berbagai kondisi saat proses pengumpulan dan pemrosesan. Kesulitan prosedur plebotomi dapat menyebabkan hemolysis. Seperti buruknya penusukan jarum kedalam vena, penarikan kembali "plunger" pada syringe yang terlalu cepat, kemungkinan adanya kebocoran udara karena jarum yang tidak pas serta penanganan spesimen yang tidak hati hati saat proses transportasi. ${ }^{14}$

Rekomendasi perbaikan yang disarankan untuk mengurangi kejadian sampel hemolisis yaitu pengajuan pelatihan phlebotomy yang ditujukan kepada perawat agar memiliki kemampuan yang sama dalam penanganan spesimen laboratorium. Perawat memiliki peran penting dalam pengambilan dan penanganan sampel serta dapat memberikan informasi yang akurat sebelum pasien dilakukan pemeriksaan laboratorium. ${ }^{17}$. Pelatihan perawat tidak saja mampu mempertahankan turnaround time hasil laboratorium bahkan dapat mengurangi waktu ditahap pra analitik ${ }^{18}$

Penelitian yang di lakukan Brijesh et al tahun 2013 menyatakan bahwa kesalahan pada tahap pra analitik dapat dicegah dengan mudah melalui pelatihan dan penggunaan standar operasional prosedur yang tepat disetiap tahap pengumpulan spesimen. Untuk mencegah terjadinya kesalahan dalam proses pengumpulan spesimen pelatihan phlebotomy dapat diselenggarakan sebagai pelatihan yang berkelanjutan agar memahami bahwa pelatihan tersebut mengurangi risiko terjadinya kesalahan. ${ }^{7}$ Hal serupa juga dijelaskan dari penelitian yang di lakukan oleh NY Lee tahun 2019 yang menyatakan bahwa pengurangan kesalahan tahap pra-analitik dapat diupayakan melalui pendidikan dan pelatihan phlebotomy agar laboratorium dapat menghasilkan laporan yang akurat dan cepat. ${ }^{20}$

Visual management digunakan sebagai media informasi dan edukasi yang dapat mempermudah perawat mengetahui bagaimana penanganan spesimen laboratorium. Informasi tersebut berisikan daftar penggunaan tabung pemeriksaan sesuai kebutuhan, cara melakukan proses homogenisasi yang tepat serta hal hal yang perlu diperhatikan seperti cara melakukan labelling yang tepat di tabung pemeriksaan. Visual management merupakan salah satu tools Lean penting yang digunakan untuk implementasi Lean. Manajemen visual merupakan alat penting dalam implementasi Lean yang dapat memberikan dampak positif terhadap kinerja operasional serta mempersingkat waktu penyelesaian. ${ }^{19}$

Upaya perbaikan secara terus menerus dilakukan dengan dokumentasi serta standardisasi. Standar operasional prosedur (SOP) sangat penting dalam menjaga kinerja agar tetap konsisten. SOP memastikan konsistensi, kualitas setiap kegiatan yang dilakukan. SOP harus tersedia di area kerja dan diakses dengan mudah oleh setiap petugas kesehatan. Setiap petugas harus paham dan memiliki pengetahuan yang sama setiap kegiatan yang akan dilakukan ${ }^{14}$. Usulan pembuatan paket standar pemeriksaan laboratorium bertujuan memudahkan dokter jaga melakukan proses input order pemeriksaan laboratorium ke dalam sistem informasi rumah sakit. Dokter jaga tidak perlu menginput satu persatu jenis pemeriksaan yang akan diperiksa.

Pengadaan kebutuhan mesin printer stiker label identitas pasien di unit rawat inap memudahkan perawat jika stiker identitas habis, perawat dapat mencetak stiker identitas pasien secara mandiri, diharapkan penggunaan stiker identitas pasien yang tidak standar tidak terjadi kembali. Adanya SPO serah terima sampel, dapat mengidentifikasi segera jika ada penggunaan stiker identittas yang tidak sesuai. 


\section{KESIMPULAN}

Rata rata waktu pemeriksaan pra analitik 27 menit 39 detik dengan waktu terlama 2 jam 27 menit 12 detik, hal tersebut disebabkan menunggu dikirim kembali spesimen pemeriksaan dikarenakan spesimen hemolisis, spesimen belum dilakukan order pemeriksaan. Kegiatan yang tidak memberikan nilai tambah sebesar $50.89 \%$ dan yang memberikan nilai tambah $49.10 \%$ Pemborosan yang sering terjadi disebabkan karena delays (waiting time), defect dan over processing. Akar masalah yang sering terjadi disebabkan karena jumlah ATLM belum sesuai dengan Analisis Beban Kerja, belum meratanya sosialiasasi Panduan penanganan spesimen laboratorium, mengoptimalisasi komunikasi efektif antar perawat, HCA dan ATLM terutama pengantaran dan serah terima spesimen. Penyelenggaraan pelatihan phlebotomy bagi perawat Unit Rawat Inap dan Instalasi Gawat Darurat agar dampak pra analitik dapat di minimalisasi. Diperlukan penyederhanaan proses order pemeriksaan untuk memudahkan dokter melakukan order pemeriksaan. Serta menyediakan mesin printer stiker identitas pasien di Unit Rawat Inap memudahkan perawat mencetak stiker identitas pasien secara mandiri. Visual management sebagai media edukasi dalam penanganan spesimen laboratorium diharapkan dapat membantu perawat dalam penanganan spesimen pasien rawat inap.

\section{UCAPAN TERIMA KASIH}

Peneliti mengucapkan terimakasih kepada RS XYZ di Depok Jawa Barat atas kesediannya sebagai institusi tempat penelitian. Rekan rekan ATLM atas kerjasamanya selama proses observasi berlangsung.

\section{DAFTAR PUSTAKA}

1. Sonmez C, Yıldız U, Akkaya N, Taneli F. Preanalytical Phase Errors: Experience of a Central Laboratory. Cureus. 2020;12(3).

2. Wankar A. Study of determination of laboratory turnaround time in tertiary care hospital in India. Int $\mathbf{J}$ Res Med Sci. 2014;2(4):1396.
3. Neogi S, Mehndiratta M, Gupta S, Puri D. Pre-analytical phase in clinical chemistry laboratory. J Clin Sci Res. 2016;5(3):171.

4. Letelier P, Guzmán N, Medina G, Calcumil L, Huencho P, Mora J, et al. Workflow optimization in a clinical laboratory using Lean management principles in the pre-analytical phase. $\mathrm{J}$ Med Biochem. 2021;40(1):26-32.

5. Lippi G, Guidi GC. The preanalytical phase in quality assurance. Qual Assur Pathol Lab Forensic, Tech Ethical Asp. 2011;(October 2015):3-13.

6. Plebani M, Sciacovelli L, Aita A, Chiozza ML. Harmonization of preanalytical quality indicators. Biochem Medica. 2014;24(1):105-13.

7. Saurav Patra MD, Brijesh Mukherjee* AK Das. Pre-Analytical Errors in the Clinical Laboratory and How To Minimize Them. Int $\mathbf{J}$ Bioassays. 2013;2(3):551-3.

8. Najat D. Prevalence of pre-analytical errors in clinical chemistry diagnostic labs in Sulaimani City of Iraqi Kurdistan. PLoS One. 2017;12(1):1-13.

9. Graban M, Padgett S. Lean laboratories: Competing with methods from Toyota. Lab Med. 2008;39(11):645-8.

10. Inal TC, Goruroglu Ozturk O, Kibar F, Cetiner S, Matyar S, Daglioglu G, et al. Lean six sigma methodologies improve clinical laboratory efficiency and reduce turnaround times. J Clin Lab Anal. 2018;32(1):1-5.

11. Gupta S, Kapil S, Sharma M. Improvement of laboratory turnaround time using lean methodology. Int J Health Care Qual Assur. 2018;31(4):295-308.

12. Gaspersz V, Fontana A. Lean Six Sigma for Manufacturing and Service Industries.: Vinchristo Publication. 2011.

13. Atay A, Demir L, Cuhadar S, Saglam G, Unal H, Aksun S, et al. Clinical biochemistry laboratory rejection rates due to various types of preanalytical errors. 2014;376-82.

14. Nouraldein M, Hamad M. Quality 
Assurance for Clinical Laboratory. LAP LAMBERT Academic Publishing; 2020.

15. BJ S, C S. Study on "Pre-analytical Errors in a Clinical Biochemistry Laboratory:" The Hidden Flaws in Total Testing. Biochem Anal Biochem. 2019;08(01):24-32.

16. Graban M. Lean hospitals: improving quality, patient safety, and employee engagement. CRC press Taylor and Prancis Group; 2016.

17. Farooqui T, Hm MBA, Administration H. Preanalytical Errors in Laboratory Their Consequences and Measures to Reduce Them. 2017;1-10.

18. Khalifa M, Khalid P. Improving Laboratory results turnaround time by reducing pre analytical phase. Stud Health Technol Inform. 2014;202(July):71-4.

19. Isack HD, Mutingi $M$, Kandjeke $H$, Vashishth A, Chakraborty A. Exploring the adoption of Lean principles in medical laboratory industry: Empirical evidences from Namibia. Int J Lean Six
Sigma. 2018;9(1):133-55.

20 N Y Lee, Types and Frequencies of Pre Analytical Errors in the Clinical Laboratory at the University Hospital Of Kores, Clin.Lab.2019190512

21 Bob Sproul 2019. Teory of Constrains, Lean and Six Sigma Improvement Methodology Making the Case for Integration: Edited by Routledge/Prductivity Press.1 edition

22 Arifin, and Amal Chalik Sjaaf.2018. "Analisis Kebutuhan Tenaga Ahli Teknologi Laboratorium Medik Berdasarkan Beban Kerja Di Unit Laboratorium Klinik Rumah Sakit Santa Maria Pekan Baru." Jurnal ARSI 4:210-22

23 Cahyaningtyas, Amalis, Hanny Handayani, and Aaat Yatnikasari. 2020."Gambaran Pelaksanaan Serah Terima Antar Shift Di Rumah Sakit X Jakarta."Holistik Jurnal Kesehatan 14 (3):

90.https://doi.org/10.33024/hjk.v4i3.29 68 